\title{
Chitosan Nanocomposite Mesoporous Membranes: Mechanical and Barrier Properties as a Function of Temperature
}

\author{
Irene S. Fahim ${ }^{1,2}$, Wael Mamdouh ${ }^{2,3} \&$ Hanadi G. Salem ${ }^{1,2}$ \\ ${ }^{1}$ Department of Mechanical Engineering, School of Sciences and Engineering (SSE), The American University in \\ Cairo (AUC), AUC Avenue, P.O. Box 74, New Cairo 11835, Egypt. \\ ${ }^{2}$ Yousef Jameel Science and Technology Research Center (YJSTRC), School of Sciences and Engineering (SSE), \\ The American University in Cairo (AUC), AUC Avenue, P.O. Box 74, New Cairo 11835, Egypt. \\ ${ }^{3}$ Department of Chemistry, School of Sciences and Engineering (SSE), The American University in Cairo (AUC), \\ AUC Avenue, P.O. Box 74, New Cairo 11835, Egypt. \\ Correspondence: Irene Fahim, Department of Mechanical Engineering, School of Sciences and Engineering (SSE), \\ The American University in Cairo (AUC), AUC Avenue, P.O. Box 74, New Cairo 11835, Egypt. Tel: \\ 002-010-0182-2221. E-mail: rico4000@ aucegypt.edu
}

Received: April 20, 2015 Accepted: May 28, 2015 Online Published: June 26, 2015

doi:10.5539/jmsr.v4n4p1 URL: http://dx.doi.org/10.5539/jmsr.v4n4p1

\begin{abstract}
This work investigates the influence of the type and wt.\% of nanofillers on the tensile strength behaviour and barrier properties of fabricated chitosan (CS) mesoporous membranes and their nanocomposites using graphene (G) and fullerene (F) nanofillers. Non cross-linked chitosan (NCLCS) as well as cross-linked chitosan (CLCS) solutions with sodium tripolyphosphate (TPP) were both mixed with G and F nanofillers with different wt.\%. NCLCS membranes displayed yield tensile strength of 24MPa while the CLCS membranes displayed a much lower yield tensile strength of 2.87MPa. The addition of $\mathrm{G}$ and $\mathrm{F}$ nanofiller enhanced the yield tensile strength of the CS membranes up to 45MPa. However, the increase in \% elongation for CLCS membranes was 75\% higher than that for NCLCS ones. Furthermore, the results revealed that there was a significant effect of the operating temperature on the membrane pore size, which decreased the tensile strength and the barrier of the produced membranes. The enhancement of the tensile properties of polymer nanocomposites membranes (PNC) membranes is crucial to avoid film fracture or delamination. Moreover, the addition of nanofillers improve the barrier properties of PNC membranes, thus the membranes are used in packaging and current filtration techniques. In this work, experimental as well as statistical analysis of the fabricated CS membranes and their yield tensile strength and \% elongation data are presented. This study presents the effect of the filler type, the filler content and the cross-linking of CS membranes on tensile strength behaviour both experimentally as well as theoretically.
\end{abstract}

Keywords: pore size, nanocomposites, nanoparticles, membranes

\section{Introduction}

Membrane technology is one of the most promising solutions to air pollution. Membranes are fabricated either from natural or synthetic polymers (Mackenzie, 1999). Although synthetic membranes are widely used as valuable scientific and technical tools, they are not well defined in terms of their structure and function (Olness, 1995). They are usually less selective and less energy efficient. The preparation of natural polymer membranes and their utilization on a large industrial scale is a recent development that gained substantial importance for sustainable development and environmental preservation. In addition, natural polymers are becoming attractive for separation of molecular mixtures due to their porous nature (Strathmann, 2006). Most importantly is that the separation is performed by physical means without chemically altering the constituents of the mixture. Natural polymer membranes attracted significant interest in a broad range of applications such as water treatment, separation membranes, food packaging, tissue engineering, and drug delivery (Mackenzie, 1999). The mechanical properties of PNC membranes (\% elongation and tensile strength) determine their application (Strathmann, 2006). The objective of this work is to study the tensile properties of natural polymer membranes used for packaging and separation, where membranes are subjected to mechanical stresses arising from the particles that need to be filtered. PNC membranes reach their optimum performance characteristics with enhanced tensile strength. This increases the membrane's durability and resistance to wear in service (Strathmann, 2006). However, it was reported that 
natural polymer membranes had their functional limitations that restricted their widespread application in packaging and separation. The main limitations are their brittleness, thermal instability, low tensile strength, high vapor and oxygen permeability, and poor mechanical stiffness (Kim et al, 1995). Weak mechanical strength of natural polymers was due to their porous structure. To overcome the mechanical strength deterioration, several physical and chemical treatments were performed to natural polymers such as chitosan, to enhance the mechanical properties due to their importance in different applications. CS is one of the most promising polymers that have been widely used in the preparation of CS membranes for various uses: for example for pervaporation, ultra filtration, reverse osmosis, gas separation, and purification processes or drug delivery (Kim et al., 1995).

CS contains abundant amino and hydroxyl groups, which enable nanoparticles formulation via both physical and chemical cross-linking. Covalent cross-linking is usually achieved by treatment of CS solutions by glutaraldehyde, which reacts with the amino groups on the CS chains (Leo et al., 2005). Ionic cross-linking of chitosan, on the other hand, is a typical non-covalent interaction, which can be realized by the association with negatively charged multivalent ions such as TPP. Physical cross-linking is more promising method since cross-linking is a reversible process and could largely avoid potential toxicity of the reagents (Kawashima et al., 1985). Diverse efforts have been made to obtain CS nanoparticles via TPP cross-linking following the pioneering work of Calvo (Calvo et al., 1997). A number of studies on the cross-linking reaction have been reported and showed that it is mainly influenced by the size and type of the cross-linker agent and the functional groups of CS. The smaller the molecular size of the cross-linker, the faster the cross-linking reaction since its diffusion is easier (Murphy, 1994; Chang et al., 2000). Different studies showed that CS cross-linked with TPP has high chemical stability together with membrane flexibility compared to other cross-linking agents (Muzzarelli, 1986; Basan \& Gümüsdereliolu, 2002; Hamdi et al., 2001; Knaul et al., 1999; Kumar, 2000).

The incorporation of inorganic nanofillers dispersed within natural polymeric matrices at a nano-scale level produces polymer nanocomposite (PNCs) membranes with enhanced mechanical properties (Koros, 2002). The two-dimensional single-layer $\mathrm{G}$, the basic building block for naturally occurring graphite, has currently attracted tremendous attention especially because of its unique structure and extraordinary electronic and mechanical properties. The nanocomposite materials combine the advantages of the matrix ranging from flexibility, processability of polymers, and the selectivity, together with mechanical strength and thermal stability of the inorganic fillers (Morooka \& Kusakabe, 1999; Tsapatis \& Gavalas, 1999). The sheet-like nanoparticles (such as graphene) offer the weakest increase in viscosity that causes clustering, and accordingly have the smallest fraction of bridging chains, and provide the greatest reinforcement (Vaia \& Giannelis, 2001; Starr et al., 2004; Hooper \& Schweizer, 2005). On the other hand, fullerene interactions are highly favorable, as they promote nanoparticles dispersion due to chain bridging between the nanoparticles and better absorption and transportation of penetrants (Hooper \& Schweizer, 2006; Gersappe, 2002; Patel et al., 2004; Shekhawat et al., 2003). This results in favorable selectivity and permeability of the matrix (Zimmerman et al., 1997).

Another significant property to evaluate the performance of the membranes is their ability to control the rate of permeation of different species. The two models used, which are also mentioned in literature to describe the mechanism of permeation, are illustrated in Figure 1a. One model is the pore flow model in which permeants are transported by pressure driven convective flow through tiny pores. Separation occurs because one of the permeants is filtered from some of the pores in the membrane through which other permeants move. The second model shown in Figure 1b. is the solution diffusion model in which permeants dissolve in the membrane material and then diffuse through the membrane down a concentration gradient. In case of gas diffusion, the gas flux is driven by the concentration gradient of absorbed molecules within the polymer matrix. The permeants are separated because of the differences in the solubility of the materials in the membrane and the differences in the rates at which materials diffuse through the membrane (Baker, 2000). In 1940, the solution diffusion model was used to explain the transport of gases through polymeric membranes. Diffusion, the basis of the solution diffusion model, is the process by which matter is transported from one part of the system to another by a concentration gradient. If a concentration gradient is formed in the medium, the transport of matter will occur from high concentration to low concentration region. This concept was first recognized by Ficks (Baker, 2000).

The model utilized in this work to evaluate the barrier properties is the solution diffusion model. It was used to determine the barrier property in terms of permeability, which is dependent on the diffusion coefficient of gas and the solubility coefficient of that gas in the polymer matrix, and compare it with experimental results. Finite element modeling was used in the current work to predict the diffusion behaviour of a porous material through the entire thickness of the membrane. The diffusion model was formed in ABAQUS, a finite element solver commonly used for mass diffusion modeling. It creates simulations to predict the change in concentration of gases passing through the membrane thickness. The governing equations for this steady state mass diffusion model are extensions of 
Fick's equations: they allow for non-uniform solubility of the diffusing substance in the membrane and for mass diffusion driven by gradients of temperature and pressure. The basic solution variable is normalized concentration. It was compared with experimental results and the simulations were refined accordingly (Kumar, 2011). The simulations took into account the change of the diffusion coefficient and the solubility with the increase in temperature, the type of filler, and the wt.\% of nanofiller. To the best of our knowledge, this is a unique study that combines theoretical mass diffusion results and experimental tensile strength results.
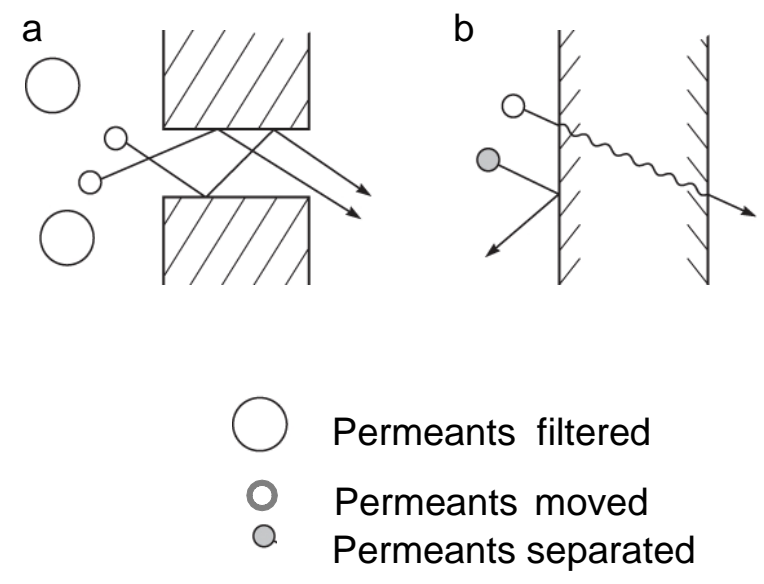

Figure 1a. Pore flow model and 1b. Solution diffusion model (Baker, 2000)

\section{Materials \& Experimental Procedures}

\subsection{Materials}

Shrimp Chitosan, $\geq 93 \%$ (w/w), was purchased from Primex as shown in Figure 2. Chemicals used for dissolving chitosan were purchased from Sigma Aldrich. These included $\mathrm{NaOH} ; \mathrm{HCl}$; acetic acid (Ac-OH, 99\% purity); sodium tripolyphosphate (TPP), used to synthesize chitosan nanoparticles; phenolphthalein (phph, 99\% purity), used as an indicator for $\mathrm{NaOH}$ in testing liquid permeability of thin films; and methanol (99.9\% purity), used for cleaning glassware.
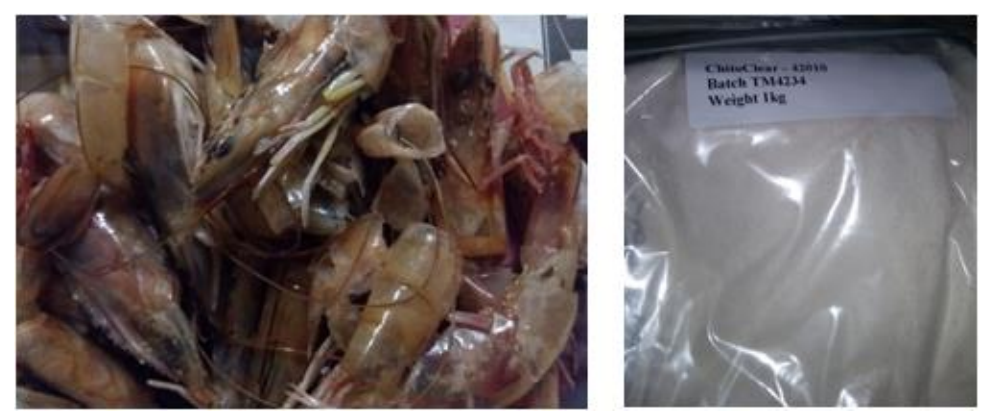

Figure 2. Shrimp Shells toused in Chitosan Production

To prepare the CLCS membranes, $0.2 \mathrm{gm}$ of CS was dissolved in $2 \%$ acetic acid at room temperature with continuous stirring. $0.033 \mathrm{gm}$ TPP were dissolved in $11 \mathrm{~mL}$ distilled $\mathrm{H}_{2} \mathrm{O}$ and added drop-wise onto the CS solution during the homogenization at 10 000rpm for 30min using a Polytron homogenizer PT 10-35GT.

G-nanofiller, shown in Figure 3a. (Sky Spring Nanomaterials, Inc. USA), and F-nanofiller, shown in Figure $3 b$. (Carbon 60, 99.5+\%, SES Research, USA), were used to produce the PNC thin films. Graphene is a one-atom-thick planar sheet of carbon atoms, densely packed together into a honeycomb shaped crystal lattice. It is the basic structural element of several carbon allotropes including graphite, carbon nanotubes and fullerenes. The 
difference in morphology (Flaky versus spherical) and nano cluster size between $\mathrm{F}$ and $\mathrm{G}$ had a significant effect on the tensile and barrier properties of the membranes.
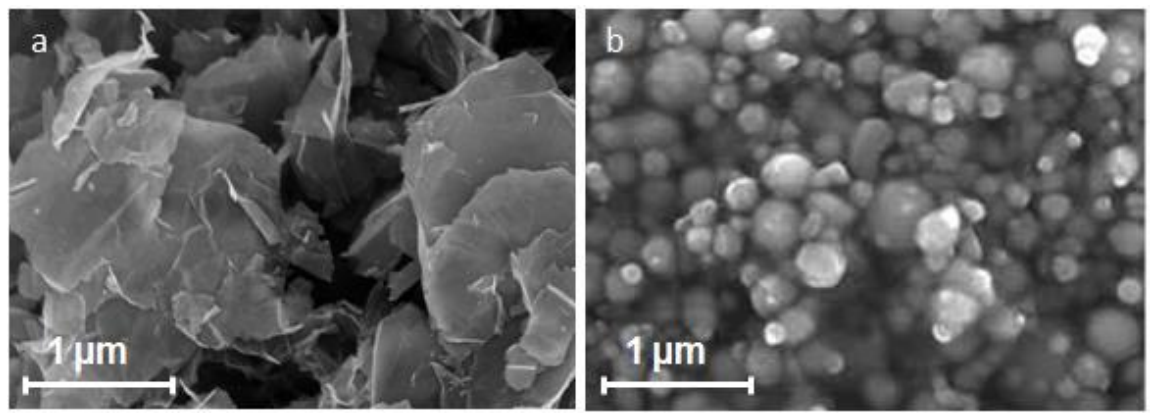

Figure 3. SEM Image for a. G-nanofiller b. F-nanofiller

\subsection{Film Processing}

CLCS and NCLCS solutions were mixed with two nanofillers (F and G) with $0.1,0.5,1$ wt. \% by solvent mixing. Mixing occurred with constant stirring for 60 minutes with a VWR® Standard Analog Shaker to form a clear homogeneous solution. The solutions were used to produce non-cross-linked CS nanocomposites (NCLCS/G and NCLCS/F), as well as the cross-linked CS nanocomposite (CLCS/G and CLCS/F) thin films. The NCLCS and CLCS filtrates were poured into two separate flattened containers and left to dry at room temperature to form CS thin films with a $2 \mathrm{~mm}$ thickness. The dry, thin films obtained from the NCLCS and CLCS solutions are shown in Figures $4 \mathrm{a}$ and $4 \mathrm{~b}$. The same procedure was used for the CLCS/G, CLCS/F, NCLCS/G, and NCLCS/F. The as-received $\mathrm{F}$ and $\mathrm{G}$-nanofiller diameters were $10 \mu \mathrm{m}$ and $15 \mu \mathrm{m}$ respectively. Upon sonication and forming a solution, the $\mathrm{F}$ and $\mathrm{G}$ were transformed to clusters of size $2 \mathrm{~nm}$ and $10 \mathrm{~nm}$ respectively (Perry et al., 2013)

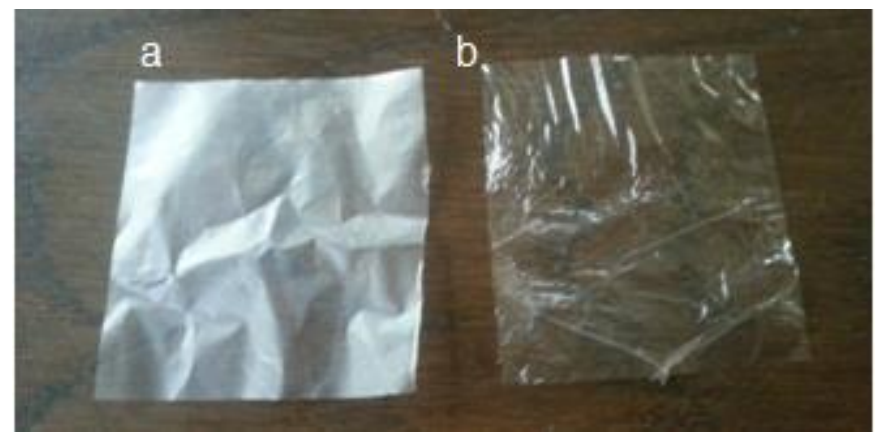

Figure 4. Macrographs for the Fabricated a. NCLCS b. CLCS Membranes, Respectively

\subsection{Tensile Properties Characterization}

The yield tensile strength and \% elongation (ductility) of the previously prepared CS membranes and nanocomposites was evaluated through an axial tensile test. The test was conducted using an Instron universal testing machine with $100 \mathrm{KN}$ capacity. To insure the axial uniform load distribution on the membrane thin sheets, a fixture was designed as a transition between the flat grips of the machine and the thin films. The \% elongation for all CS membranes at three different temperatures $\left(23,30\right.$, and $\left.60^{\circ} \mathrm{C}\right)$ was also measured during tensile testing. The guidelines for the dimensions of the membrane samples were cut in accordance with ASTM Standard Method D 882-91 (ASTM, D882-91). The initial grip separation was set at $30 \mathrm{~mm}$. The tensile tests were conducted at a preselected strain of $0.4 \mathrm{~mm} / \mathrm{mm}$ for the NCLCS and 1.8 for the CLCS membranes. The testing was performed at the preselected strain values to insure that testing occurred within the uniform plastic deformation. A strain rate of $10 \mathrm{~mm} / \mathrm{min}$ was employed for all tested samples. The tensile behaviour of the fabricated membranes was tested as a function of temperature at 23,30 and $60^{\circ} \mathrm{C}$ to investigate the influence of stretching of the membranes as a function of the operating temperatures on the pore size and shape. 


\subsection{Finite Element Analysis}

The Finite Element Analysis (FEA) is a numerical method for solving problems of engineering and mathematical physics. Abaqus/Standard provides a modeling of steady-state diffusion of the fabricated membranes using governing equations that are an extension of Fick's equations. The input data for ABAQUS software included the geometry of the membrane, which was constructed with a specific thickness, after which the material properties were specified. These included diffusivity and the solubility of oxygen gas through the fabricated membranes (Duncan et al., 2005). The input data varied according to the material it would diffuse in, whether pure polymer or polymer reinforced nanocomposite. The first step was constructing the membrane followed by assigning each material to the solid homogenous section. This was followed by specifying the steady state mass diffusion and then specifying a time increment and a time period for the step. Abaqus/Standard then proceeded through the step accordingly. The boundary conditions were applied at the inlet to the nodes in the mass diffusion element to prescribe values of normalized concentration as shown in Figure 5. This was followed by applying a surface concentration flux, as concentration fluxes were the only loads that could be applied in a mass diffusion analysis step. Finally, meshing was optimized to assure convergence of the solution when choosing the DCC3D8 element (the 8-node convection/diffusion brick). There were no applicable element controls for this type of element (Duncan et al., 2005). The normalized concentration output shown in Figure 5. was measured through the thickness of the one-layer membrane $(2 \mathrm{~mm})$. The normalized concentration of the diffusing molecules passes through a diffusion pathway from high concentration at the inlet to lower concentration at the outlet. The output was calculated at three different temperatures $\left(23,30,60^{\circ} \mathrm{C}\right)$.

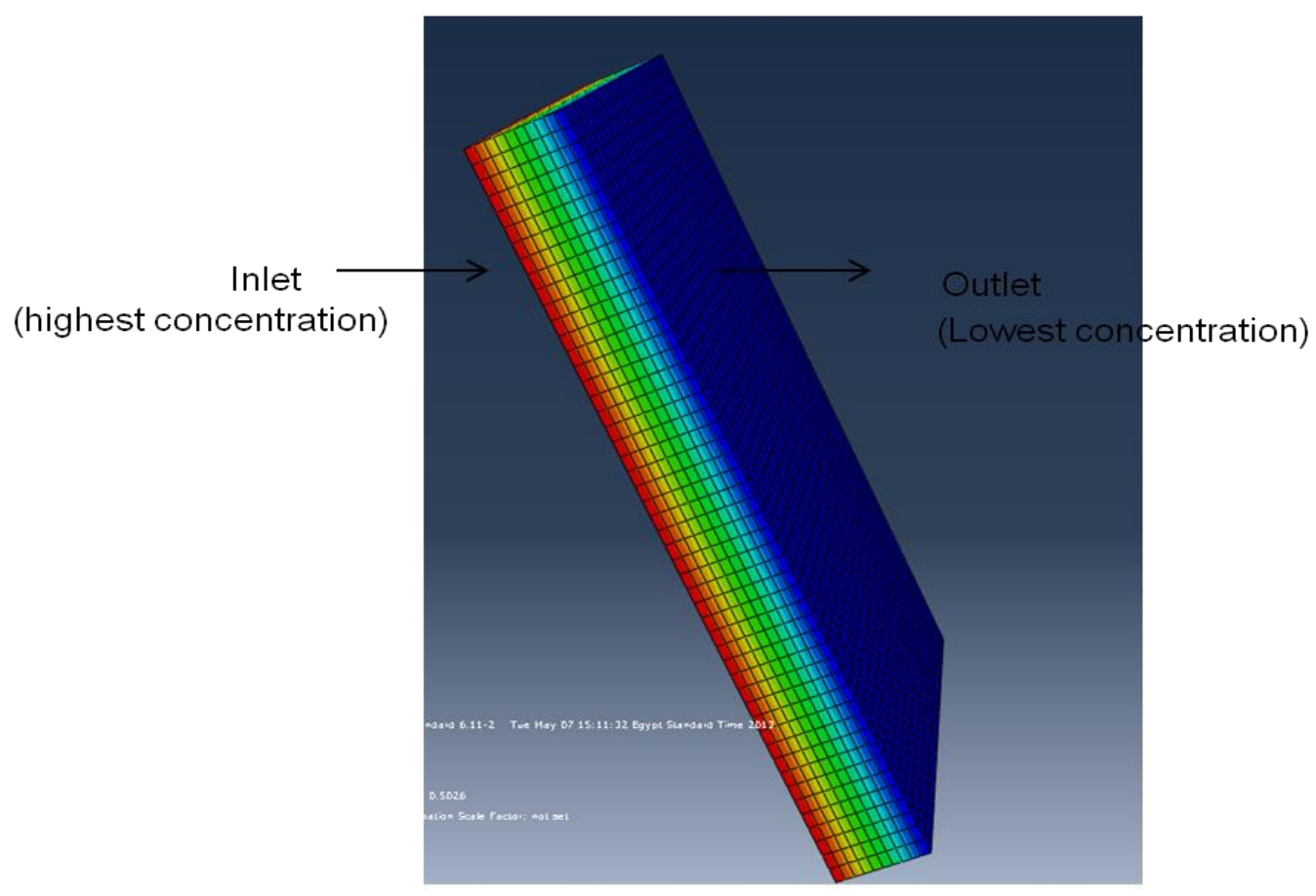

Figure 5. Inlet and Outlet Normalized Concentration through the Membrane Thickness

\subsection{Statistical Analysis}

For better interpretation of data and to derive the representative conclusions about the influence of the various parameters on the membrane properties, a statistical analysis was performed using Design Expert software (Myers \& Montgomery, 2002). The parameters included in the statistical analysis are illustrated in Table 1. The output of Design Expert 9.0.4.1.included three responses: tensile strength, diffusion time, and pore size. The analysis of variance showed the parameters that have significant effect. The significant factors have values with low p-value (Probability>F) where $\mathrm{p}$ was less than 0.0001 (Myers \& Montgomery, 2002). 
Table 1.The Factors and Their Combinations Used for the Statistical Analysis

\begin{tabular}{ll}
\hline A & Temperature $\left(23,30,60^{\circ} \mathrm{C}\right)$ \\
$\mathrm{B}$ & Polymer (NCLCS-CLCS) \\
$\mathrm{C}$ & Type of filler (Graphene, Fullerene) \\
$\mathrm{D}$ & $\mathrm{Wt} . \%$ of filler $(0.1,0.5,1 \%)$ \\
$\mathrm{AB}$ & Interaction between temperature and type of polymer \\
$\mathrm{AC}$ & Interaction between temperature and type of filler \\
$\mathrm{AD}$ & Interaction between temperature and wt. \% of filler \\
$\mathrm{BC}$ & Interaction between type of polymer and type of filler \\
$\mathrm{BD}$ & Interaction between type of polymer and wt.\% of filler \\
$\mathrm{CD}$ & Interaction between type of filler and wt. \% of filler \\
\hline
\end{tabular}

Response surface methodology (RSM) was useful in this work, as it modeled three different responses: tensile strength, pore size and diffusion time. The eventual objective of RSM was to determine the optimum operating conditions for the membrane fabrication. Fitting and analyzing response surfaces was greatly facilitated by the proper choice of factorial design as it provides distribution of data points, allows model adequacy, provides precise estimates of model coefficients, provides a good profile of the prediction variance throughout the experimental region, provides reasonable robustness to insure simplicity of calculation of model parameters (Montgomery \& Runger, 2003).

\section{Results}

\subsection{Pore Size}

Our group has recently published the work related to the effect of nanofiller materials ( $G$ and $F$ ) on the pore sizes of CS membranes. The fabricated CS membranes were found to be mesoporous; NCLCS membranes showed the formation of pore size of $10 \mathrm{~nm}$, while CLCS membranes displayed 200\% coarser pore sizes and $70 \%$ higher permeability. NCLCS and CLCS membranes reinforced with G and F nanofillers showed an improvement of the barrier properties compared to plain NCLCS and CLCS membranes. This was done through filling up of the pores upon the addition of the nanofillers with different wt.\%. There was a decrease in the pore size in NCLCS membranes by $70 \%$ (with $0.1 \mathrm{wt} . \% \mathrm{G}$ ) and $80 \%$ (with $1 \mathrm{wt} . \% \mathrm{G}$ ), respectively. This was mainly due to the barrier effect of G-nanofiller morphology and size. There was also a decrease in the pore size in NCLCS membranes by $50 \%$ (with $0.1 \mathrm{wt} . \% \mathrm{~F}$ ) and $60 \%$ (with $1 \mathrm{wt} . \% \mathrm{~F}$ ), respectively. Thus the nanofiller wt.\% played a crucial role in controlling the pore size of CS membranes. The cluster effect of G-nanofiller on the CS pores that led to their accumulation inside the pores of the CS membranes. This decreased the pore size of the NCLCS membranes, whereas F- nanofiller was dispersed inside the pores to an extent that allows higher permeability compared with G-nanofiller. A thorough investigation of the produced CS nanocomposite membranes by using experimental techniques such as scanning electron microscopy (SEM), average pore size measurement, liquid and gas permeability testing were reported (Fahim et al., 2015). The SEM representative images showed the dispersion of nanofillers within the polymer matrix and the nanofillers effects on the barrier properties of the membranes. The reported results helps in explaining the tensile properties in this work.

CLCS and NCLCS nanocomposite membranes with F and G-nanofillers were fabricated, and their tensile properties were investigated. The influence of the membrane chemical structure on the tensile strength and \% elongation was studied. Physical cross-linking of CS by TPP and the addition of F and G-nanofillers were found to be crucial factors affecting the tensile strength and \% elongation of the fabricated CS membranes. In the following subsections, the influence of the membrane crosslinking condition with and without nanofillers on the tensile behaviour of the films was displayed.

\subsection{Tensile Properties}

\subsubsection{Tensile Behaviour of NCLCS and CLCS Membranes}

The tensile behaviour versus strain of the plain NCLCS and CLCS membranes is shown in Figure 6. It clearly revealed higher tensile strength of 24MPa for the NCLCS compared to 2.8MPa for the CLCS membranes. CLCS membranes had coarser pore sizes compared to NCLCS. The formation of ionic cross-links between amino groups of CS and TPP groups decreased the surface area of the polymer leading to an increase in the surface area of the 
membranes' pores. Surface area was measured (using a porosimeter), it is defined as area / mass $\left(\mathrm{m}^{2} / \mathrm{g}\right.$ ) between the absolute surface area of a solid and its mass (sample weight). The surface area includes all parts of accessible inner surfaces (mainly pore wall surfaces). The surface area of the NCLCS membrane was $0.373 \mathrm{~m}^{2} / \mathrm{g}$ while the one for CLCS membrane was $0.1574 \mathrm{~m}^{2} / \mathrm{g}$. The measurements revealed the decrease in the surface area of CS upon crosslinking (Fahim et al., 2015). The decrease in tensile strength could be attributed to the coarse pore size formed in the CLCS, which promoted pore size growth and coalescence resulting in premature failure (Muzzarelli, 1986). However, in NCLCS membranes, the pore size was smaller. Therefore, the stability of the pores against growth and coalescence due to increased bonding interaction between the CS chains could have resulted in the enhanced tensile strength. (Sannan et al., 2003).

The correlation between elongation and cross-linking of polymers was not as straight-forward as was the relation between cross-linking and tensile strength. There are two important observations when using crosslinking agents that should be taken into account. Some research carried out in which crosslinking increased the tensile strength of polymers. While other research reports revealed that addition of cross linking agent decreased the tensile strength depending on several factors. \% elongation either increased or decreased depending on the chemical backbone structure of the polymer, type and density of crosslinking agent. For example, crosslinking of chitosan with glutaraldyde enhanced the tensile strength by $25 \%$ (Chan et al., 2013). On the other hand, it has been reported that crosslinking increased the elasticity of LDPE/wax blends. When the amount of crosslinker increased, a decrease in the crystallinity of the polymer occurred leading to a decrease in tensile strength (Krupa et al., 2001). Another example of chitosan films that were greatly enforced by the introduction of crosslinking agent, achieving an increased elongation of about $80 \%$, was mentioned by Kiuchi et al. (Kiuchi et al., 2008). In this work, chitosan was chemically cross-linked with TPP at ( $0.3 \%$ the weight of chitosan). Increasing this degree of crosslinking (which is not included in this chart) lead to a decrease in elongation. This conclusion agreed with the findings of Daniels et al., where increasing the concentration of the crosslinking agent increased the stiffness of the membrane (Daniels, 1989). \% elongation increased from 0.5 to $2 \%$ upon cross-linking as shown in Figure 6. Crosslinking increased elongation since the structure of the overall material changed from individual chains linked only with van der Waals forces to covalent bonds, which are few but strong. The polymer acts as a single molecule as soon as the covalent bond occurs. A further explanation of the relationship between crosslinking and increasing \% elongation can be attributed to the more flexible molecular structure resulting from ionic cross-linking (Wang et al., 1998).

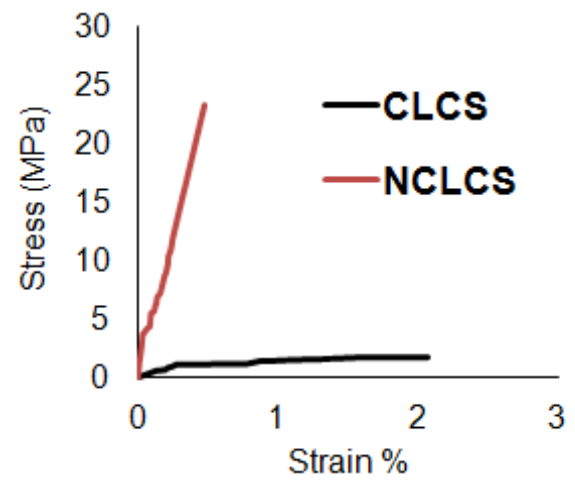

Figure 6. Stress-strain Curve for NCLCS and CLCS Membranes

\subsubsection{Effect of F and G-nanofiller Content on the Tensile Properties of NCLCS Membranes}

Figure 7. reflected the effect of addition of nanofillers ( $F$ or $G$ ) to CS matrices membranes. On using $F$ as a nanofiller in NCLCS, the tensile strength increased from 24MPa for the plain matrices up to $45 \mathrm{MPa}$ with increasing F-content up to $1 \mathrm{wt} . \%$. with an average of $46 \%$ as illustrated in Figures $7 \mathrm{a}$. The increase in tensile strength upon addition of F-nanofiller was most probably due to the rigidity of the F nanofiller and the strong interaction between the CS polymeric chains within. The clusters of F-nanofiller were dispersed within the CS polymeric chain (Shlykov et al., 2010). They reported that F improved the tensile strength of polymers to 30-40\% (Sung, 2001).

On the other hand, addition of G-nanofiller, the tensile strength of NCLCS/0.1 wt.\% G displayed was about 30MPa, which showed an increase in the tensile strength compared to NCLCS (24MPa). The strength was further increased by adding $1 \mathrm{wt}$. \% of $\mathrm{G}$ up to $40 \mathrm{MPa}$ as shown in Figure $7 \mathrm{~b}$. Accordingly, increasing G-content up to $1 \mathrm{wt} . \%$ to the 
NCLCS matrices resulted in $40 \%$ increase in tensile strength. It was reported that G improved the tensile strength of polymers to $29 \%$. The enhancement was easily explainable with the large aspect ratio and high interfacial contact area of G-nanoparticles with the polymers (Chaharmahali et al., 2014).

The increase in tensile strength with the addition of different wt.\% of $\mathrm{G}$ suggested that G-nanofiller was mechanically dispersed into the NCLCS during the wet mixing process forming a carbon network in the polymer structure. The structural arrangement of G-nanoparticles within the NCLCS offers higher interfacial adhesion then CS without G nanofillers. one of the possible binding scenarios could be related to the layered structure of G-nanofiller that facilitate sliding of polymer chains next to each other. However, the higher tensile strength upon addition of F-nanofiller was attributed to the small clusters of F-nanofiller that were better dispersed within the CS polymeric chains.
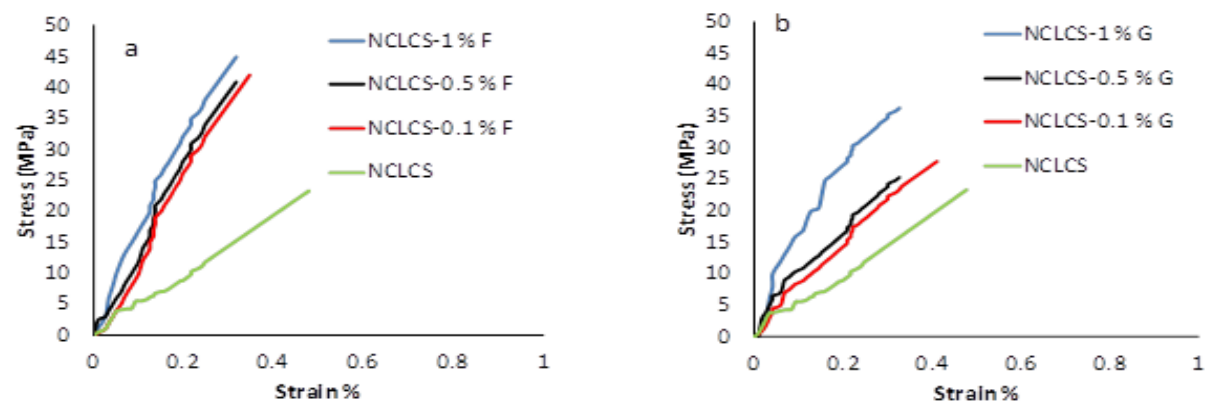

Figure 7. Stress-strain Curve for NCLCS Matrices as a Function of Increasing the Wt.\% of a. F and b. G.

The reduction in the ductility of the composite with increase in the F and G-nanofillers was due to the increase in the deformation of a rigid interfacial interaction between $\mathrm{F}$ and the polymer matrix, and $\mathrm{G}$ and the polymer matrix. The rigidity of bonding between F, G and the NCLCS matrix led to a weak \% elongation, as illustrated in Figure 7b. However, upon comparing the \% elongation in NCLCS/F membranes and NCLCS/G membranes, one would conclude that the same behaviour occurred and the nanocomposite was tending toward brittle behavior (Siracusa, 2008).

\subsubsection{Effect of F and G-nanofiller Content on the Tensile Properties of CLCS Membranes}

The addition of nanofillers ( $F$ or $G$ ) to CLCS matrices membranes enhanced their tensile strength. The tensile strength of CLCS/ $0.1 \mathrm{wt} . \% \mathrm{~F}$ displayed about 10MPa. The tensile strength was further increased by adding $1 \mathrm{wt}$. \% of $\mathrm{F}$ up to 20MPa, as shown in Figure 8a. The tensile strength of CLCS/0.1 wt.\% G displayed 9MPa, which showed an increase in the tensile strength compared to CLCS (2.8MPa). The tensile strength was further increased by adding $1 \mathrm{wt}$. \% of $\mathrm{G}$ up to $17 \mathrm{MPa}$, as shown in Figure 8b. Accordingly, increasing G-content up to $1 \mathrm{wt} . \%$ to the CLCS matrices resulted in $80 \%$ increase in tensile strength, while causing a decrease of $20 \%$ in elongation due to the rigidity of the nanocomposite (Siracusa, 2008). However, the higher tensile strength upon addition of F-nanofiller was attributed to the small clusters of F-nanofiller that were better dispersed within the CS polymeric chains.
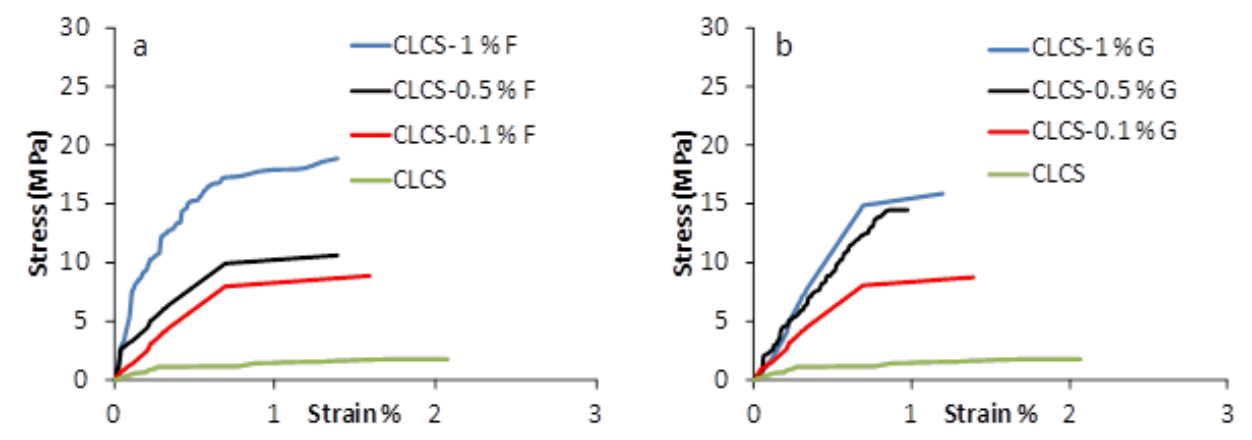

Figure 8. Stress-strain Curve for CLCS with Different Wt.\% of a. F and b. G 


\section{2.4 Effect of Increasing Temperature on the Tensile Properties of CS Membranes}

The results referred to in the previous sections were recorded at room temperature. However, in order to study the influence of temperature on the tensile strength and \% elongation of the CS mesoporous membranes as a function of the cross-linking and the nanofillers content, the tensile testing of the fabricated membranes were also carried out at temperatures of 30 and $60{ }^{\circ} \mathrm{C}$. The tensile strength and pore size for all CS membranes were measured at a preselected strain of (Strain $=0.4 \%$ for NCLCS $-1.8 \%$ for CLCS membranes) and listed in Table 2. It is worth mentioning that these tensile strength results were recorded prior to membrane failure.

It was clear from the listed results in Table 2. that the NCLCS tensile strength was higher than that of the CLCS, while the average pore size for the NCLCS was lower than that of the CLCS. Increasing the temperature resulted in the decrease of tensile strength of NCLCS membranes by $8 \%$ and $20 \%$ and an increase in the pore size by $30 \%$ and $90 \%$ at 30 and $60{ }^{\circ} \mathrm{C}$, respectively as shown in Table 2 . This could be due to the increase in the movement of CS chains leading to enlargement of the pore sizes in the different CS membranes (Alexeev, 2010). The effect of increasing temperature on polymer nanocomposites was also reported by Nam et al., high temperatures decrease the polymer nanocomposites stiffness and it becomes more ductile leading to a decrease in tensile strength (Nam et al., 2001). (Appendix B include SEM images showing the pore size of NCLCS and CLCS membranes).

Upon the addition of $0.1 \mathrm{wt} . \% \mathrm{~F}$ to NCLCS membranes there was a decrease in tensile strength of $30 \%$ and $20 \%$ and an increase in pore by size $70 \%$ and $100 \%$ at 30 and $60{ }^{\circ} \mathrm{C}$, respectively. Upon the addition of $1 \mathrm{wt} . \% \mathrm{~F}$ to NCLCS membranes there was a decrease in tensile strength of $45 \%$ and $53 \%$ and an increase in pore by size $62 \%$ and $91 \%$ at 30 and $60^{\circ} \mathrm{C}$, respectively as shown in Table 2 . The same behavior of decreasing tensile strength with an increase in pore size was observed in CLCS membranes upon the addition of F-nanofiller. However, the decrease of tensile strength is larger than that of NCLCS, as explained in section 3.2.1.

On the other hand, upon the addition of $0.1 \mathrm{wt} . \% \mathrm{G}$ to NCLCS membranes there was a decrease in tensile strength of $10 \%$ and $30 \%$ and an increase in pore by size $22 \%$ and $66 \%$ at 30 and $60^{\circ} \mathrm{C}$, respectively. Upon the addition of $1 \mathrm{wt} . \% \mathrm{G}$ to NCLCS membranes there was a decrease in tensile strength of $5 \%$ and $28 \%$ and an increase in pore by size 50\% and 50\% at 30 and $60{ }^{\circ} \mathrm{C}$ respectively, as shown in Table 2 . The same behavior was observed in CLCS membranes upon the addition of G-nanofiller. Although the tensile strength decreased as a result of pore enlargement, the tensile strength of NCLCS $/ 1 \mathrm{wt} . \% \mathrm{G}$ at $60^{\circ} \mathrm{C}(29 \mathrm{MPa})$ was still considered a reliable membrane, suitable for packaging applications even at ambient temperatures up to $60^{\circ} \mathrm{C}$ (Siracusa et al., 2008).

Table 2.Tensile Strength for CS Membranes at $23,30,60{ }^{\circ} \mathrm{C}$

\begin{tabular}{lllllll}
\hline Temperature & $\mathbf{2 3}^{\circ} \mathbf{C}$ & & $\mathbf{3 0}^{\circ} \mathbf{C}$ & & $\mathbf{6 0}^{\circ} \mathbf{C}$ & \\
\hline & T.S. & P.S. & T.S. & P.S. & T.S. & P.S. \\
Membranes & MPa & nm & MPa & nm & MPa & nm \\
\hline NCLCS & 24.0 & 10.6 & 22.8 & 13.4 & 19.4 & 15.4 \\
NCLCS-0.1\%F & 40.0 & 2.6 & 27.5 & 4.4 & 19.9 & 5.2 \\
NCLCS-0.5\% F & 43.0 & 2.5 & 30.5 & 4.1 & 20.2 & 4.9 \\
NCLCS-1\%F & 45.0 & 2.4 & 36.0 & 3.9 & 21.1 & 4.6 \\
NCLCS-0.1\%G & 30.8 & 1.8 & 27.2 & 2.2 & 24.2 & 3.0 \\
NCLCS-0.5\%G & 35.3 & 1.1 & 32.5 & 1.6 & 26.2 & 2.5 \\
NCLCS-1\%G & 40.1 & 0.0 & 38.8 & 1.0 & 29.8 & 2.0 \\
CLCS & 2.8 & 19.3 & 1.2 & 29.5 & 0.8 & 33.3 \\
CLCS-0.1\%F & 9.0 & 18.1 & 8.6 & 26.4 & 7.9 & 29.4 \\
CLCS-0.5\%F & 18.0 & 17.2 & 11.5 & 18.2 & 11.5 & 26.4 \\
CLCS-1\%F & 20.0 & 16.0 & 17.3 & 4.5 & 15.2 & 25.1 \\
CLCS-0.1\%G & 10.9 & 15.3 & 8.6 & 17.0 & 5.2 & 20.0 \\
CLCS-0.5\%G & 14.2 & 9.2 & 10.1 & 11.5 & 7.4 & 15.2 \\
CLCS-1\%G & 17.0 & 4.0 & 13.2 & 5.0 & 10.2 & 7.0 \\
\hline
\end{tabular}

Note. T.S=Tensile Strength, P.S.=Pore size. 


\subsubsection{Effect of Increasing Temperature on Barrier Properties of CS Membranes Using FEA}

The increase in temperature had a direct effect on the mass diffusion. High diffusion rates occurred at low $\%$ of nanofillers as a function of increasing temperature, as shown in Appendix A. Tables A1. and A2. show the effect of increasing temperature on the normalized concentration of both NCLCS and CLCS and their nanocomposite membranes along the membrane thickness. It is clear that the increase in temperature from $23^{\circ} \mathrm{C}$ to $30^{\circ} \mathrm{C}$ and $60^{\circ} \mathrm{C}$ revealed higher (normalized concentration) diffusion due to increase in the pore size. The normalized concentration at $0.2 \mathrm{~mm}$ in NCLCS was $767(\mathrm{C} / \mathrm{S})$ and increased to $777(\mathrm{C} / \mathrm{S})$ at $30^{\circ} \mathrm{C}$. The same behavior was displayed upon raising the temperature to $60^{\circ} \mathrm{C}$. A normalized concentration of $797(\mathrm{C} / \mathrm{S})$ was measured as shown in Table A1.

The normalized concentration, shown in Table A2. for CLCS membranes at $0.2 \mathrm{~mm}$ distance, was higher (780 $(\mathrm{C} / \mathrm{S}))$ than that of NCLCS membranes $(767(\mathrm{C} / \mathrm{S}))$, which agreed with the exhibited increase of pore size upon cross-linking. The similar effect of increasing temperature was illustrated in Table A2. for CLCS membranes at $0.2 \mathrm{~mm}$ distance; the increase of normalized concentration from $780(\mathrm{C} / \mathrm{S})$ to $800(\mathrm{C} / \mathrm{S})$ at $30^{\circ} \mathrm{C}$ was followed by an increase to $840(\mathrm{C} / \mathrm{S})$ at $60{ }^{\circ} \mathrm{C}$. This established the correlation between pore size increase and the increase in temperature (Morehouse et al. 2006), where the increase in temperature increased the normalized concentration of the membranes due to increase in pore size with stretching the membranes.

\subsection{Statistical Analysis}

In order to find the optimum and most desirable membranes for filtration and packaging applications, statistical analysis was performed. The input for the analysis was the experimental results of the collective properties (porosity and tensile strength) of CLCS and NCLCS with different wt. $\%$ of $\mathrm{G}$ and $\mathrm{F}$ at 23,30 , and $60^{\circ} \mathrm{C}$. The experimental results used are mentioned in sections 4.3.2, 4.3.3 and 4.3.8.

RSM was useful in applying the statistical analysis as it modeled three different responses: i) tensile strength, ii) pore size and iii) diffusion time. The responses were influenced by several parameters including temperature (23, 30 , and $60^{\circ} \mathrm{C}$ ), polymer (CLCS and NCLCS), nanofiller type (F and G) and wt. $\%$ of the nanofiller $(0.1,0.5$, and 1 wt.\%). It is worth mentioning that the input data for tensile strength were prior to membrane failure. The ultimate objective of RSM was to determine the optimum operating conditions for the membrane fabrication (Bettinger \& Chinnici, 1991).

\subsubsection{Analysis of Variance}

The main aim for this experiment was investigating the effect of $\mathrm{F}$ and G-nanofillers and temperature on the tensile strength, porosity, and diffusion time of CS nanocomposite membranes. There were 2 replicates to each data point to ensure that the data was correct. The 48 runs were entered in random order. This randomized test sequence was necessary to prevent the effects of unknown nuisance variables and avoid contaminating the results. To be more objective in this work, an analysis was performed to test the differences between the mean of each factor at every specified response. The appropriate procedure for testing the equality of several means was the analysis of variance (ANOVA) (Montgomery \& Runger, 2003). The ANOVA was suitable for analysis of these types of experiments. The name analysis of variance was derived from the partitioning of total variability into its component parts. It states that the total variability in the given data as measured by the total corrected sum of squares can be partitioned into a sum of squares of the differences between the treatment average and the grand average plus a sum of squares of the differences of observations within treatments from the treatment average. A further step in this method was calculating the mean square of the treatments and the error. F is the ratio of the mean square of the treatments to the mean square error. In this work, the ANOVA showed that the mean square of treatments is larger than the error mean square and the $\mathrm{p}$ value can be computed (if it is less than 0.0001 than the factor is significant) (Bettinger \& Chinnici, 1991). The factors and their interactions highlighted in Table 3 are the most significant.

The Design Expert output chart shown in Figure 9. highlighted the significant factors within each response. The significant factors for tensile strength response included temperature, crosslinking of polymer, and the wt.\% of filler. The higher the temperature, the lower the tensile strength in NCLCS membranes as shown in Figure 9a. CLCS has lower tensile strength than NCLCS, as illustrated in Figure 9b. The increase in the wt.\% of the nanofiller led to an increase in the tensile strength as shown in Figure $9 \mathrm{~b}$. Figure $9 \mathrm{c}$ shows the wt $\%$ of filler with temperature intersecting with the lines representing tensile strength. The analysis of variance outcomes corresponded to the experimental results in section 3.2.3 where CLCS had a lower tensile strength than NCLCS. In section 3.2.2 and 3.2.3 the addition of nanofiller increased the tensile strength of both NCLCS and CLCS membranes. The results in section 3.2.4 established the same effect of temperature on lowering tensile strength of the membranes as the software output. 
Table 3. ANOVA for the Three Responses

\begin{tabular}{lllllll}
\hline & F & P value & $F$ & P value & F & P value \\
\hline A-Temp & 35.62 & $<0.0001$ & 46.26 & $<0.0001$ & 45.38 & $<0.0001$ \\
A^2 $^{\wedge}$ & 6.7 & 0.015 & 17.69 & 0.0002 & 26.34 & $<0.0001$ \\
B-Polymer & 118.42 & $<0.0001$ & 337.43 & $<0.0001$ & 47.03 & $<0.0001$ \\
C-Filler & 0.1 & 0.75 & 57.37 & $<0.0001$ & 34.88 & $<0.0001$ \\
D-\% of filler & 23.35 & $<0.0001$ & 40.92 & $<0.0001$ & 24.72 & $<0.0001$ \\
AB & 1.49 & 0.23 & 12.12 & 0.002 & 0.12 & 0.735 \\
AC & 3.53 & 0.07 & 3.21 & 0.083 & 3.56 & 0.069 \\
AD & 2.79 & 0.06 & 2.57 & 0.074 & 1.69 & 0.196 \\
BC & 1.29 & 0.26 & 10.54 & 0.003 & 1.93 & 0.175 \\
BD & 0.85 & 0.48 & 6.58 & 0.002 & 2.64 & 0.069 \\
CD & 0.15 & 0.93 & 12.61 & $<0.0001$ & 7.65 & 0.0007 \\
\hline
\end{tabular}

Note. $\mathrm{F}=$ Ratio of Mean Square, $\mathrm{P}=$ Probability.
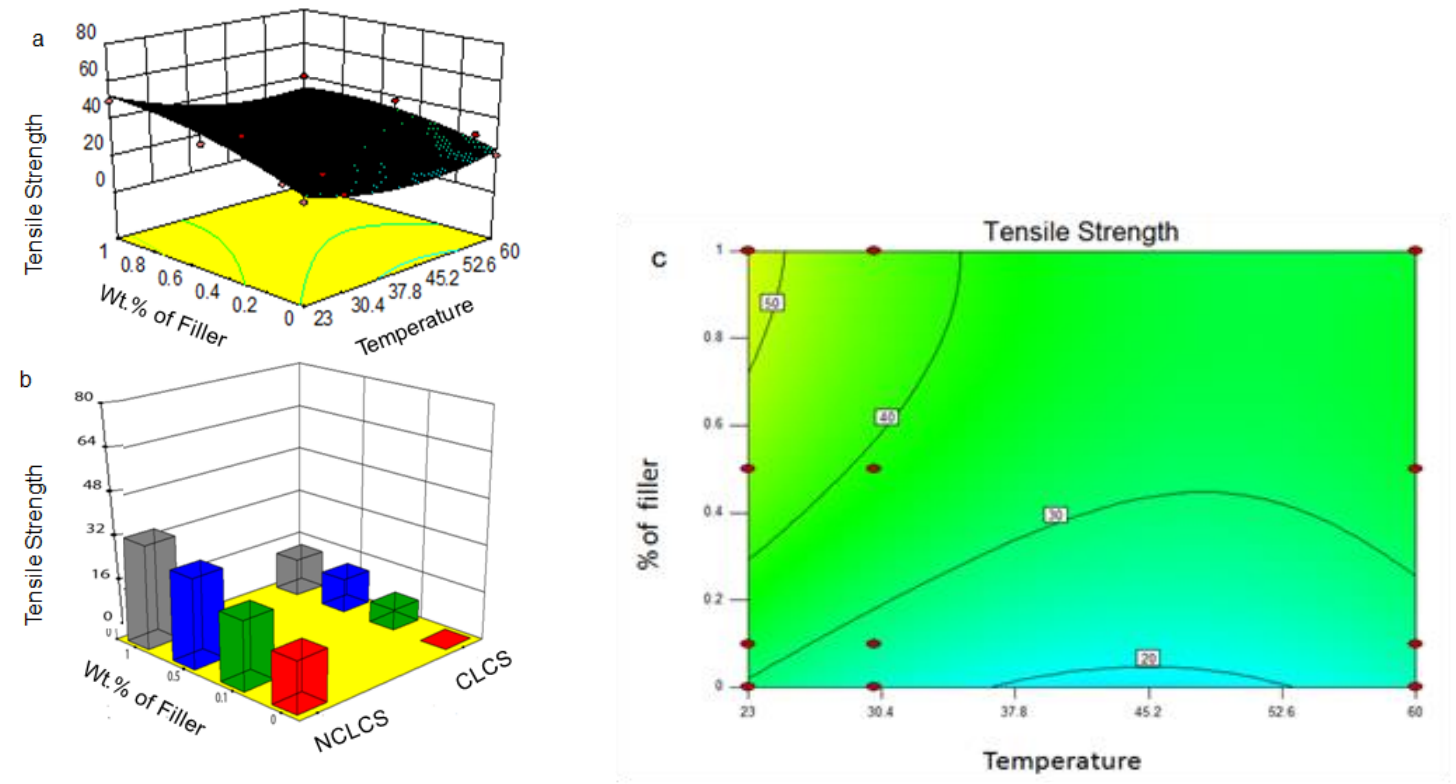

Figure 9. Output Charts for NCLCS Membranes Showing Effect of Temperature, Cross-linking of the Polymer, and the Wt.\% of the Nanofiller on the Tensile Strength Response

For the pore size response, there are several factors which were significant, including temperature, cross-linking of polymer, nanofiller type, the wt.\% of filler, and the interaction between the nanofiller type and the wt.\% of the filler. As the temperature increased, pore size increased in NCLCS membranes, as shown in Figure 10a. The effect of increase of wt.\% of filler is quite clear in Figure 10b. Figure 10c shows the wt \% of filler with temperature intersecting with the lines representing pore size. As wt.\% of filler increased, the pore size decreased, thus increasing the barrier effect of the fabricated membranes. The experimental results were similar in sections 3.2.4. where the pore size decreased in Table 2. due to effect of nanofillers. 

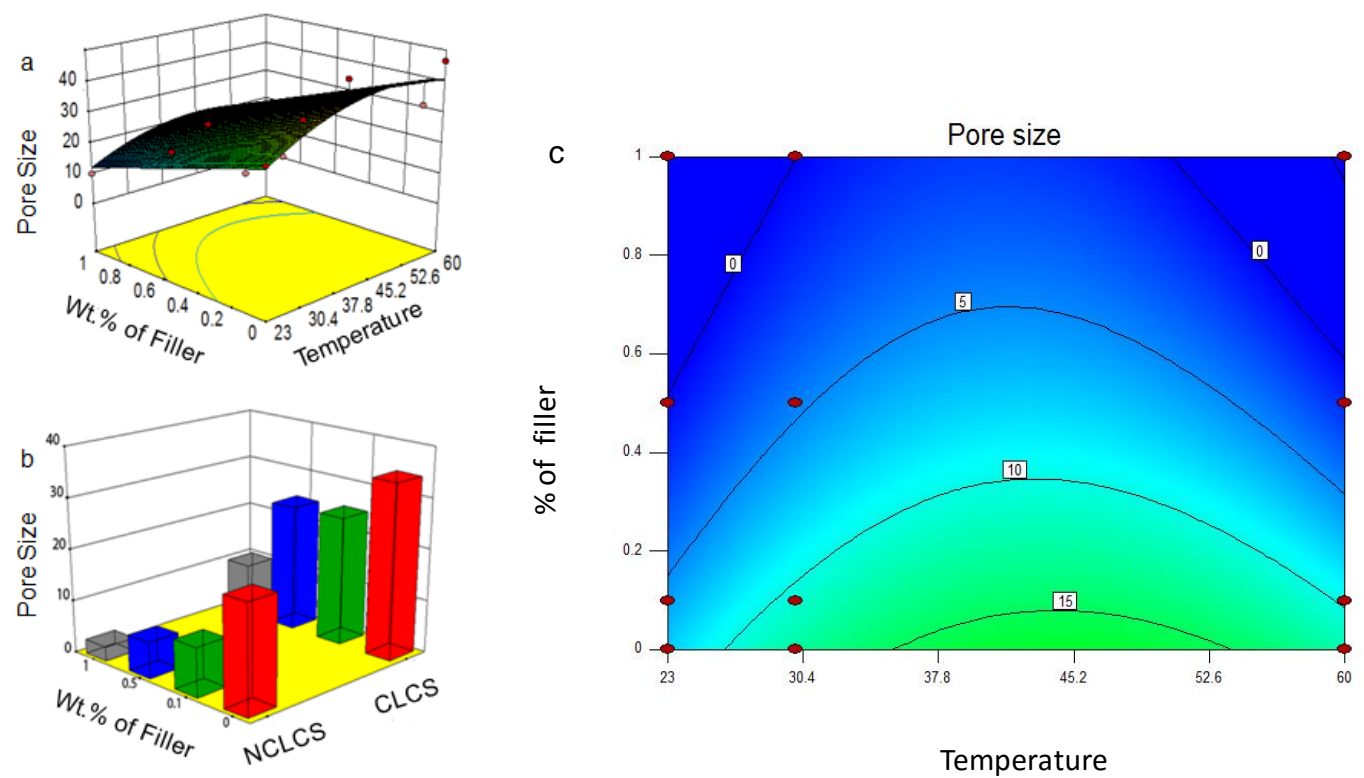

Figure 10. Output Charts for NCLCS Membranes Showing Effect of Temperature and the Wt.\% of the Nanofiller on the Pore Size Response

The significant factors for the third response, the diffusion time, were the temperature, cross-linking of polymer, nanofiller type, and the wt.\% of filler. The increase in temperature decreased the diffusion time due to enlargement of the pore size in NCLCS membranes because of the heating effect as revealed in Figure 11a. The increase in the wt.\% of the nanofiller showed a prolonged diffusion time due to blocking of the pores as illustrated in Figure 11b. Figure 11c shows the wt $\%$ of filler with temperature intersecting with the lines representing diffusion time.
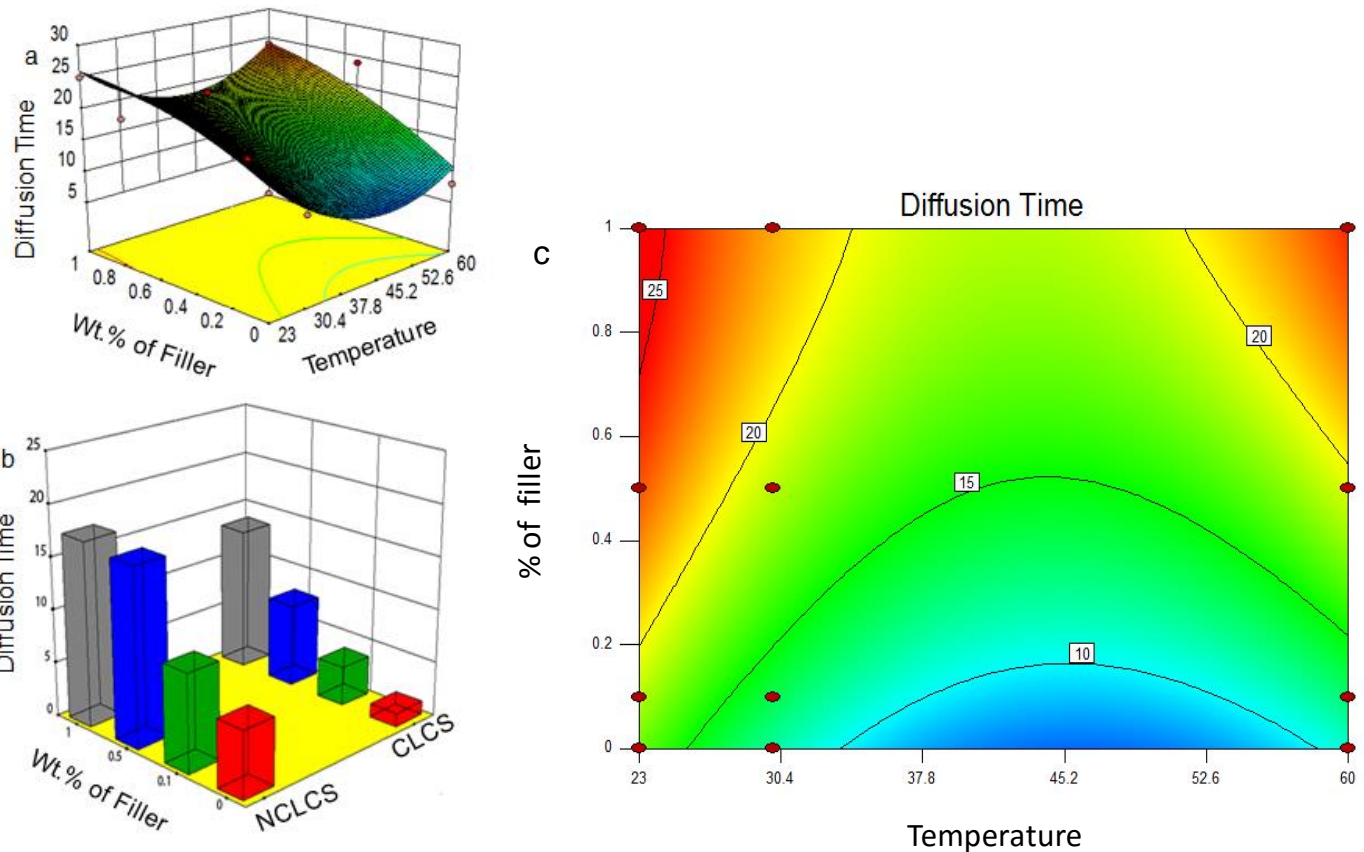

Figure 11. Output Charts for NCLCS membranes Showing Effect of Temperature and Wt.\% of Filler on Diffusion Time Response 


\section{Conclusions}

$\mathrm{G}$ and $\mathrm{F}$ addition resulted in the enhancement of the tensile properties of CS membranes by increasing the yield tensile strength of NCLCS membranes by $46 \%$ for F and $40 \%$ for G. This was due to the structural arrangement of nanoparticles within the CS membranes offers higher interfacial adhesion within the polymer matrix. This could be related to the G-nanofiller flaky structure versus the interaction of F nanofillers with the surrounding atoms. The crosslinking of CS membranes increased the \% elongation for CLCS by more than $75 \%$. depending on the time and density of the crosslinking agent. Moreover the addition of nanofillers improved the membranes' gas barrier properties by decreasing the pore size in the NCLCS, CLCS conditions. The CS membranes' pore size decreased due to the filling up of pores with $\mathrm{G}$ and $\mathrm{F}$ nanoparticles The preferred temperature range from 23 to $30^{\circ} \mathrm{C}$ offered the most suitable environment in which tensile strength and pore size were adequate to packaging applications. Upon increasing the temperature to $60^{\circ} \mathrm{C}$, the tensile strength decreased due to pore size increase which had a negative effect on the performance of the membranes. However, NCLCS/1 wt.\% G retains its properties ( permeability and tensile strength). The optimum membrane pore size, tensile strength, and operating temperature were calculated by RSM. This method highlighted some of the filtration applications of the fabricated PNC membranes. The optimum membranes were selected according to the size of the permeant that needs to be filtered out. NCLCS/1wt. \% G could be used to filter gases. CLCS/1 wt. \% F could be used for smoke filtration.

\section{Acknowledgments}

The authors acknowledge the financial support received from the American University in Cairo (AUC) through Faculty Support Research Grant and also the Arab Academy for Science and Technology (ASRT), Egypt, through Ph.D. support grant.

\section{References}

Alexeev, V., Keberg, E., \& Evmenenko, G. (2010). Development and characterization of chitosan film. International Journal of Engineering Research and Applications, 1(2), 292-299. Retrieved from http://www.ijera.com/papers/vol\%201\%20issue\%202/012292299AL.pdf.

Baker, R. (2004). Membrane technology and applications (2nd ed.). Chichester: J. Wiley. http://dx.doi.org/10.1002/0470020393.

Basan, H., Gümüşderelíoğlu, M., \& Orbey, T. (2002). Diclofenac sodium releasing pH-sensitive monolithic devices. International Journal of Pharmaceutics, 245, 191-198. http://dx.doi.org/10.1016/s0378-5173(02)00 $350-2$

Bettinger, D., \& Chinnici, J. (1991). Utiliization of response surface modeling to evaluate the interaction between aflatoxin B1 and caffeine on egg adult viability in drosophila meganogaster. Virginia Journal of Science, 42. Retrieved from http://www.vacadsci.org/vjsArchives/V42/42-3/42-311.pdf

Calvo, P., Remunan-Lopez, C., Vila-Jato, J., \& Alonso, M. (1997). Novel hydrophilic chitosan-polyethylene oxide nanoparticles as protein carriers. Journal of Applied Polymer Science, 63, 125-132. http://dx.doi.org/10.1002/ (sici)1097-4628(19970103)63:1<125::aid-app13>3.0.co;2-4

Chaharmahali, M., Hamzeh, Y., Ebrahimi, G., Ashori, A., \& Ghasemi, I. (2014). Effects of nano-graphene on the physico-mechanical properties of bagasse/polypropylene composites. Polymer Bulletin, 71, 337-349. http://dx.doi.org/10.1007/s00289-013-1064-3

Chan, M. Y., Husseinsyah, S., \& Sam S. T. (2013). Chitosan/Corn Cob Biocomposite Films by Cross-linking with Glutaraldehyde. Biosources, 8, 2. http://dx.doi.org/10.15376/biores.8.2.2910-2923

Chang, K., Ming-Chih T., \& Cheng, F. (2000). Kinetics and products of the degradation of chitosan by hydrogen peroxide. Journal of Agriculture Food Chemistry, 49, 4845-4851. http://dx.doi.org/10.1021/jf001469g

Choi, M., Kwon, K., Park, C., Kim, S., \& Hahn, S. (1999). Estimate of the thermal diffusivity of films with a sandwich structure by using pulsed transient analysis and AC calorimetry. Journal of the Korean Physical Society, 34. Retrieved from http://www.springer.com/physics/journal/40042

D882-91 Standard test method for tensile testing of thin plastic sheeting (film). (n.d.). Retrieved from http://www.astm.org/Standards/D882.htm

Daniels, C. (1989). Polymers: Structure and properties, Lancaster: CRC Press. http://dx.doi.org/10.1002/pi.49802 20314 
Duncan, B., Urquhart, J. \& Roberts, S. (2005). Review of measurement and modeling of permeation and diffusion in polymers. NPL Report. Retrieved from http://resource.npl.co.uk/materials/polyproc/iag/october2005/ depc_mpr_012.pdf

Fahim, I., Marei, N., Salem H., G., \& Mamdouh, W. (2015). Effect of graphene and fullerene nanofillers on controlling the pore size and physicochemical properties of chitosan nanocomposite mesoporous membranes. Journal of Nanomaterials, 10. http://dx.doi.org/10.1155/2015/979561

Gersappe, D. (2002). Molecular mechanisms of failure in polymer nanocomposites. Physical Review Letters, 89, 058301. http://dx.doi.org/10.1103/physrevlett.89.058301

Hamdi, G., Ponchel, G., \& Duchêne, D. (2001). Formulation of epichlorohydrin cross-linked starch microspheres. Journal of Microencapsulation, 18, 373-383. http://dx.doi.org/10.1080/02652040010019505

Hooper, J. \& Schweizer, K. (2005). Contact aggregation, bridging and steric stabilization in dense polymer- matrix mixtures. Macromolecules, 38, 8858-8869. http://dx.doi.org/10.1021/ma051318k

Hooper, J., \& Schweizer, K. (2006). Theory of phase separation in polymer nanocomposites. Macromolecules, 39 , 5133-5142. http://dx.doi.org/10.1021/ma060577m

Kawashima, Y., Handa, T., Kasai, A., Takenaka, H., Lin, S., \& Ando, Y. (1985). Novel method for the preparation of controlled-release theophylline granules coated with a polyelectrolyte complex of sodium polyphosphate-chitosan. Journal of Pharmaceutical Sciences, 74, 264-268. http://dx.doi.org/10.1002/jps.2600740308

Kiuchi, H., Kai W., \& Inoue, Y. (2007). Preparation and characterization of poly(ethylene glycol) crosslinked chitosan films, Journal of Applied Polymer Science, 107, 3823-3830. http://dx.doi.org/10.1002/app.27546

Knaul, J. Z., Hudson, S. M., \& Creber, K. A. M. (1999). Mechanical properties of chitosan fibers. Journal of Applied Polymer Science, 72, 1721-1732. http://dx.doi.org/10.1002/(sici)1097-4628(19990624)72:13<1721:: aid-app8>3.0.co;2-v

Koros, W. (2002). Gas separation membranes: Needs for combined materials science and processing approaches. Macromolecular Symposia, 188, 13. http://dx.doi.org/10.1002/1521-3900(200211)188:1<13::aid-masy13> 3.0.co;2-w

Krupa, I., \& Luyt, S. (2001). Mechanical properties of uncrosslinked and crosslinked linear low-density polyethylene/wax blends, Journal of Applied Polymer Science, 81, 973-980. http://dx.doi.org/10.1002/app. 1519

Lopez-Leo, T., Carvalho, E., Seijo, B., Ortega-Vinuesa, J., \& Bastos-Gonzalez, D. (2005). Physicochemical characterization of chitosan nanoparticles: Electrokinetic and stability behaviour. J. Colloid Interface Science, 283, 344. http://dx.doi.org/10.1016/j.jcis.2004.08.186

Mackenzie, K. (1999). Parasites as pollution indicators in marine ecosystems: A proposed early warning system, Marine Pollution Bulletin, 38, 959. http://dx.doi.org/10.1016/s0025-326x(99)00100-9

Montgomery, D., \& Runger, G. (2003). Applied statistics and probability for engineers. New York: John Wiley \& Sons. http://dx.doi.org/10.1080/03043799408928333

Morehouse, J., Lloyd, D., Freeman, B., Lawler, D., Liechti, K., \& Becker, E. (2006). Modeling the stretching of microporous membranes. Journal of Membrane Science, 283, 430-439. http://dx.doi.org/10.1016/j.memsci. 2006.07.024

Morooka, S., \& Kusakabe, K. (1999). Microporous inorganic membranes for gas separation. Materials Research Bulletin, 24, 25. Retrieved from http://journals.cambridge.org/action/displayAbstract?fromPage=online \&aid=9028564\&fileId=S088376 9400051873

Muzzarelli, R. (1986). Chitin in nature and technology. New York: Plenum Press. http://dx.doi.org/10.1007/978$1-4613-2167-5$

Myers, R. H., \& Montgomery, D. C. (1995). Response surface methodology: Process and product optimization using designed experiments. New York: Wiley. http://dx.doi.org/10.2307/1270613

Nam, P. H. Maiti, P., Okamoto, M., Kotaka, T., Hasegawa, N., \& Usuki, A. (2001). A hierarchical structure and properties of intercalated polypropylene/clay nanocomposites. Polymer, 42, 9633. http://dx.doi.org/10.1 016/s0 032-3861(01)00512-2 
Olness, A. (1995). Water quality: Prevention, identification and management of diffuse pollution. Journal of Environmental Quality, 24, 383. http://dx.doi.org/10.2134/jeq1995.00472425002400020024x

Patel, N., Zielinski, J., Samseth, J., \& Spontak, R. (2004). Effects of pressure and nanoparticle functionality on $\mathrm{CO} 2$-selective nanocomposites derived from crosslinked poly(ethylene glycol). Molecular Chemistry and Physics, 205, 2409-2419. http://dx.doi.org/10.1002/macp.200400356

Ravi Kumar, M. (2000). A review of chitin and chitosan applications. Reactive and Functional Polymers, 46, 1-27. http://dx.doi.org/10.1016/s1381-5148(00)00038-9

Ross-Murphy, S. (1994). Rheological characterization of polymer gels and networks. Polymer Gels and Networks, 2, 229-237. http://dx.doi.org/10.1016/0966-7822(94)90007-8

Sannan, T., Kurita, K., \& Iwakura, Y. (1975), Studies on chitin, 1. Solubility change by alkaline treatment and film casting. Makromolecular Chemistry, 176, 1191-1195. http://dx.doi.org/10.1002/macp.1975.021760426

Shekhawat, D., Luebke, D., \& Pennline, H. (2003). A review of carbon dioxide selective membranes. U.S. Department of Energy, 9-11. http://dx.doi.org/10.2172/819990

Siracusa, V., Rocculi, P., Romani, S., \& Rosa, M. (2008). Biodegradable polymers for food packaging: A review. Trends in Food Science \& Technology, 19, 634-643. http://dx.doi.org/10.1016/j.tifs.2008.07.003

Strathmann, H. (2011). Introduction to membrane science and technology. Weinheim, Germany: Wiley-VCH Verlag \& Co. Retrieved from http://searchworks.stanford.edu/view/9371882

Sung, H., Liang, I., Chen, C., Huang, R., \& Liang, H. (2001). Stability of a biological tissue fixed with a naturally occurring crosslinking agent (genipin). Journal of Biomedical Materials Research, 55, 538-546. http://dx.doi.org/10.1002/1097-4636(20010615)55:4<538::aid-jbm1047>3.3.co;2-u

Tsapatis, M., \& Gavalas, G. (1999). Synthesis of inorganic membranes. Journal of Materials Research Science Bulletin, 24, 30-35. Retrieved from http://serials.unibo.it/cgi-ser/start/en/spogli/df-s.tcl?prog_art=4937890\& language $=$ ENGLISH\&view $=$ articoli

Vaia, R., \& Giannelis, E. (2001). Structure and dynamics of polymer layered silicate nanocomposites. Chemistry of Materials, 8, 1728. http://dx.doi.org/10.1021/cm960127g

Wang, W., Roberts, G., Domard, A., Roberts, G., \& Varum, K. (1998). Advances in chitin science. Lyon: Jacques Andre Publisher Press. http://dx.doi.org/10.1016/j.carbpol.2010.11.049

Zimmerman, C., Singh, A., \& Koros, W. (1997). Tailoring mixed matrix composite membranes for gas separations. Journal of Membrane Science, 137, 145. http://dx.doi.org/10.1016/s0376-7388(97)00194

Zuev, V., Kostromin, S., \& Shlykov, A. (2010). Mechanics of polymer nanocomposites modified with fulleroid nanofillers. Polymer Science Series A, 52(5), 532-536. http://dx.doi.org/10.1134/s0965545x10050081

\section{Appendix A}

Table A1. Normalized Concentration for NCLCS Membranes at 23, 30, $60{ }^{\circ} \mathrm{C}$

\begin{tabular}{|c|c|c|c|c|c|c|c|}
\hline $23^{\circ} \mathrm{C}$ & Nor & alized Conce & ation $(\mathrm{C} / \mathrm{S})$ & & & & \\
\hline $\begin{array}{l}\mathrm{D} . \\
(\mathrm{mm})\end{array}$ & $\begin{array}{c}\text { NCLC } \\
\text { S }\end{array}$ & $\begin{array}{c}\text { NCLCS-0.1 } \\
\% \mathrm{~F}\end{array}$ & $\begin{array}{c}\text { NCLCS-0.5 } \\
\% \mathrm{~F}\end{array}$ & $\begin{array}{c}\text { NCLCS-1 } \\
\% \mathrm{~F}\end{array}$ & $\begin{array}{c}\text { NCLCS }-0.1 \% \\
\text { G }\end{array}$ & $\begin{array}{c}\text { NCLCS-0.5 } \\
\% \mathrm{G}\end{array}$ & $\begin{array}{c}\text { NCLCS- } 1 \% \\
G\end{array}$ \\
\hline 0 & 850 & 850 & 850 & 850 & 850 & 850 & 850 \\
\hline 0.2 & 767 & 766 & 764 & 763 & 765 & 762 & 754 \\
\hline 0.4 & 684 & 682 & 678 & 676 & 680 & 674 & 658 \\
\hline 0.6 & 601 & 598 & 592 & 589 & 595 & 586 & 562 \\
\hline 0.8 & 518 & 514 & 506 & 502 & 510 & 498 & 466 \\
\hline 1 & 435 & 430 & 420 & 415 & 425 & 410 & 370 \\
\hline 1.2 & 352 & 346 & 334 & 328 & 340 & 322 & 274 \\
\hline 1.4 & 269 & 262 & 248 & 241 & 255 & 234 & 178 \\
\hline 1.6 & 186 & 178 & 162 & 154 & 170 & 146 & 82 \\
\hline
\end{tabular}




\begin{tabular}{|c|c|c|c|c|c|c|c|}
\hline 1.8 & 103 & 94 & 76 & 67 & 85 & 58 & 0 \\
\hline $30^{\circ} \mathrm{C}$ & \multicolumn{3}{|c|}{ Normalized Concentration (C/S) } & & & & \\
\hline $\begin{array}{l}\text { D. }(\mathrm{m} \\
\mathrm{m})\end{array}$ & $\begin{array}{l}\text { NCLC } \\
\text { S }\end{array}$ & $\begin{array}{c}\text { NCLCS-0.1 } \\
\% \mathrm{~F}\end{array}$ & $\begin{array}{c}\text { NCLCS-0.5 } \\
\% \mathrm{~F}\end{array}$ & $\begin{array}{c}\text { NCLCS-1 } \\
\% \mathrm{~F}\end{array}$ & $\begin{array}{c}\text { NCLCS- } 0.1 \% \\
\text { G }\end{array}$ & $\begin{array}{l}\text { NCLCS-0.5 } \\
\% \text { G }\end{array}$ & $\begin{array}{c}\text { NCLCS-1 } \% \\
\text { G }\end{array}$ \\
\hline 0 & 850 & 850 & 850 & 850 & 850 & 850 & 850 \\
\hline 0.2 & 777 & 776 & 774 & 773 & 776 & 774 & 773 \\
\hline 0.4 & 694 & 692 & 688 & 686 & 692 & 688 & 686 \\
\hline 0.6 & 611 & 608 & 602 & 599 & 608 & 602 & 599 \\
\hline 0.8 & 528 & 524 & 516 & 512 & 524 & 516 & 512 \\
\hline 1 & 445 & 440 & 430 & 425 & 440 & 430 & 425 \\
\hline 1.2 & 362 & 356 & 344 & 338 & 356 & 344 & 338 \\
\hline 1.4 & 279 & 272 & 258 & 251 & 272 & 258 & 251 \\
\hline 1.6 & 196 & 188 & 172 & 164 & 188 & 172 & 164 \\
\hline 1.8 & 113 & 104 & 86 & 77 & 104 & 86 & 77 \\
\hline $60^{\circ} \mathrm{C}$ & \multicolumn{3}{|c|}{ Normalized Concentration(C/S) } & & & & \\
\hline $\begin{array}{l}\text { D. } \\
(\mathrm{mm})\end{array}$ & $\begin{array}{l}\text { NCLC } \\
\mathrm{S}\end{array}$ & $\begin{array}{c}\text { NCLCS-0.1 } \\
\% \mathrm{~F}\end{array}$ & $\begin{array}{c}\text { NCLCS- } \\
0.5 \% \mathrm{~F}\end{array}$ & $\begin{array}{c}\text { NCLCS-1 } \\
\% \mathrm{~F}\end{array}$ & $\begin{array}{c}\text { NCLCS- } 0.1 \% \\
\text { G }\end{array}$ & $\begin{array}{l}\text { NCLCS-0.5 } \\
\% \mathrm{G}\end{array}$ & $\begin{array}{c}\text { NCLCS-1 } \% \\
\text { G }\end{array}$ \\
\hline 0 & 850 & 850 & 850 & 850 & 850 & 850 & 850 \\
\hline 0.2 & 797 & 796 & 794 & 793 & 796 & 794 & 793 \\
\hline 0.4 & 714 & 712 & 708 & 706 & 712 & 708 & 706 \\
\hline 0.6 & 631 & 628 & 622 & 619 & 628 & 622 & 619 \\
\hline 0.8 & 548 & 544 & 536 & 532 & 544 & 536 & 532 \\
\hline 1 & 465 & 460 & 450 & 445 & 460 & 450 & 445 \\
\hline 1.2 & 382 & 376 & 364 & 358 & 376 & 364 & 358 \\
\hline 1.4 & 299 & 292 & 278 & 271 & 292 & 278 & 271 \\
\hline 1.6 & 216 & 208 & 192 & 184 & 208 & 192 & 184 \\
\hline 1.8 & 133 & 124 & 106 & 97 & 124 & 106 & 97 \\
\hline
\end{tabular}

Note. $\mathrm{D}=$ Distance, NCLCS=Non Cross-linked Chitosan, F=Fullerene, G=Graphene.

Table A2. Normalized Concentration for CLCS Membranes at 23, 30, $60{ }^{\circ} \mathrm{C}$

\begin{tabular}{cccccccc}
\hline $23^{\circ} \mathrm{C}$ & \multicolumn{7}{c}{ Normalized Concentration (C/S) } \\
D. (mm) & CLCS & $\begin{array}{c}\text { CLCS-0. } \\
1 \% \mathrm{~F}\end{array}$ & $\begin{array}{c}\text { CLCS-0. } \\
5 \% \mathrm{~F}\end{array}$ & $\begin{array}{c}\text { CLCS-1 } \\
\% \mathrm{~F}\end{array}$ & $\begin{array}{c}\text { CLCS-0. } \\
1 \% \mathrm{G}\end{array}$ & $\begin{array}{c}\text { CLCS-0. } \\
5 \% \mathrm{G}\end{array}$ & $\begin{array}{c}\text { CLCS-1 } \\
\% \mathrm{G}\end{array}$ \\
\hline 0 & 850 & 850 & 850 & 850 & 850 & 850 & 850 \\
0.2 & 780 & 778 & 788 & 776 & 775 & 756 & 750 \\
0.4 & 710 & 706 & 726 & 702 & 700 & 662 & 650 \\
0.6 & 640 & 634 & 664 & 628 & 625 & 568 & 550 \\
0.8 & 570 & 562 & 602 & 554 & 550 & 474 & 450 \\
1 & 500 & 490 & 540 & 480 & 475 & 380 & 350 \\
1.2 & 430 & 418 & 478 & 406 & 400 & 286 & 250 \\
1.4 & 360 & 346 & 416 & 332 & 325 & 192 & 150 \\
1.6 & 290 & 274 & 354 & 258 & 250 & 98 & 50 \\
\hline
\end{tabular}




\begin{tabular}{|c|c|c|c|c|c|c|c|}
\hline 1.8 & 220 & 202 & 292 & 184 & 175 & 4 & 0 \\
\hline $30^{\circ} \mathrm{C}$ & \multicolumn{4}{|c|}{ Normalized Concentration (C/S) } & & & \\
\hline D. $(\mathrm{mm})$ & CLCS & $\begin{array}{c}\text { CLCS-0. } \\
1 \% \mathrm{~F}\end{array}$ & $\begin{array}{c}\text { CLCS- } 0 . \\
5 \% \mathrm{~F}\end{array}$ & $\begin{array}{c}\text { CLCS-1 } \\
\% \mathrm{~F}\end{array}$ & $\begin{array}{c}\text { CLCS- } 0 . \\
1 \% \mathrm{G}\end{array}$ & $\begin{array}{c}\text { CLCS- } 0 . \\
5 \% \mathrm{G}\end{array}$ & $\begin{array}{c}\text { CLCS-1 } \\
\% \mathrm{G}\end{array}$ \\
\hline 0 & 850 & 850 & 850 & 850 & 850 & 850 & 850 \\
\hline 0.2 & 800 & 798 & 808 & 796 & 795 & 776 & 770 \\
\hline 0.4 & 730 & 726 & 746 & 722 & 720 & 682 & 670 \\
\hline 0.6 & 660 & 654 & 684 & 648 & 645 & 588 & 570 \\
\hline 0.8 & 590 & 582 & 622 & 574 & 570 & 494 & 470 \\
\hline 1 & 520 & 510 & 560 & 500 & 495 & 400 & 370 \\
\hline 1.2 & 450 & 438 & 498 & 426 & 420 & 306 & 270 \\
\hline 1.4 & 380 & 366 & 436 & 352 & 345 & 212 & 170 \\
\hline 1.6 & 310 & 294 & 374 & 278 & 270 & 118 & 70 \\
\hline 1.8 & 240 & 222 & 312 & 204 & 195 & 24 & 20 \\
\hline $60^{\circ} \mathrm{C}$ & \multicolumn{4}{|c|}{ Normalized Concentration (C/S) } & & & \\
\hline D. $(\mathrm{mm})$ & CLCS & $\begin{array}{c}\text { CLCS-0. } \\
1 \% \mathrm{~F}\end{array}$ & $\begin{array}{c}\text { CLCS- } 0 . \\
5 \% \mathrm{~F}\end{array}$ & $\begin{array}{c}\text { CLCS-1 } \\
\% \mathrm{~F}\end{array}$ & $\begin{array}{c}\text { CLCS- } 0 . \\
1 \% \mathrm{G}\end{array}$ & $\begin{array}{c}\text { CLCS- } 0 . \\
5 \% \mathrm{G}\end{array}$ & $\begin{array}{c}\text { CLCS-1 } \\
\% \mathrm{G}\end{array}$ \\
\hline 0 & 850 & 850 & 850 & 850 & 850 & 850 & 850 \\
\hline 0.2 & 840 & 838 & 848 & 836 & 835 & 816 & 810 \\
\hline 0.4 & 770 & 766 & 786 & 762 & 760 & 722 & 710 \\
\hline 0.6 & 700 & 694 & 724 & 688 & 685 & 628 & 610 \\
\hline 0.8 & 630 & 622 & 662 & 614 & 610 & 534 & 510 \\
\hline 1 & 560 & 550 & 600 & 540 & 535 & 440 & 410 \\
\hline 1.2 & 490 & 478 & 538 & 466 & 460 & 346 & 310 \\
\hline 1.4 & 420 & 406 & 476 & 392 & 385 & 252 & 210 \\
\hline 1.6 & 350 & 334 & 414 & 318 & 310 & 158 & 110 \\
\hline 1.8 & 280 & 262 & 352 & 244 & 235 & 64 & 60 \\
\hline
\end{tabular}

Note. $\mathrm{D}=$ Distance, CLCS=Cross-linked Chitosan, $\mathrm{F}=\mathrm{Fullerene}, \mathrm{G}=$ Graphene

\section{Appendix B}

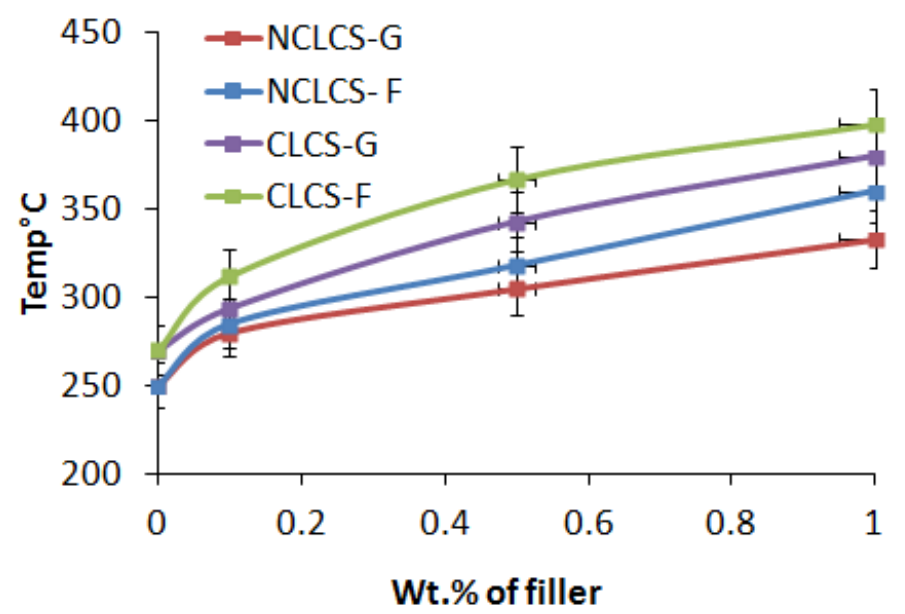

Figure 1. Glass transition temp versus wt.\% of filler for CS nanocomposite membranes as a function of $\mathrm{F}$ and $\mathrm{G}$ 

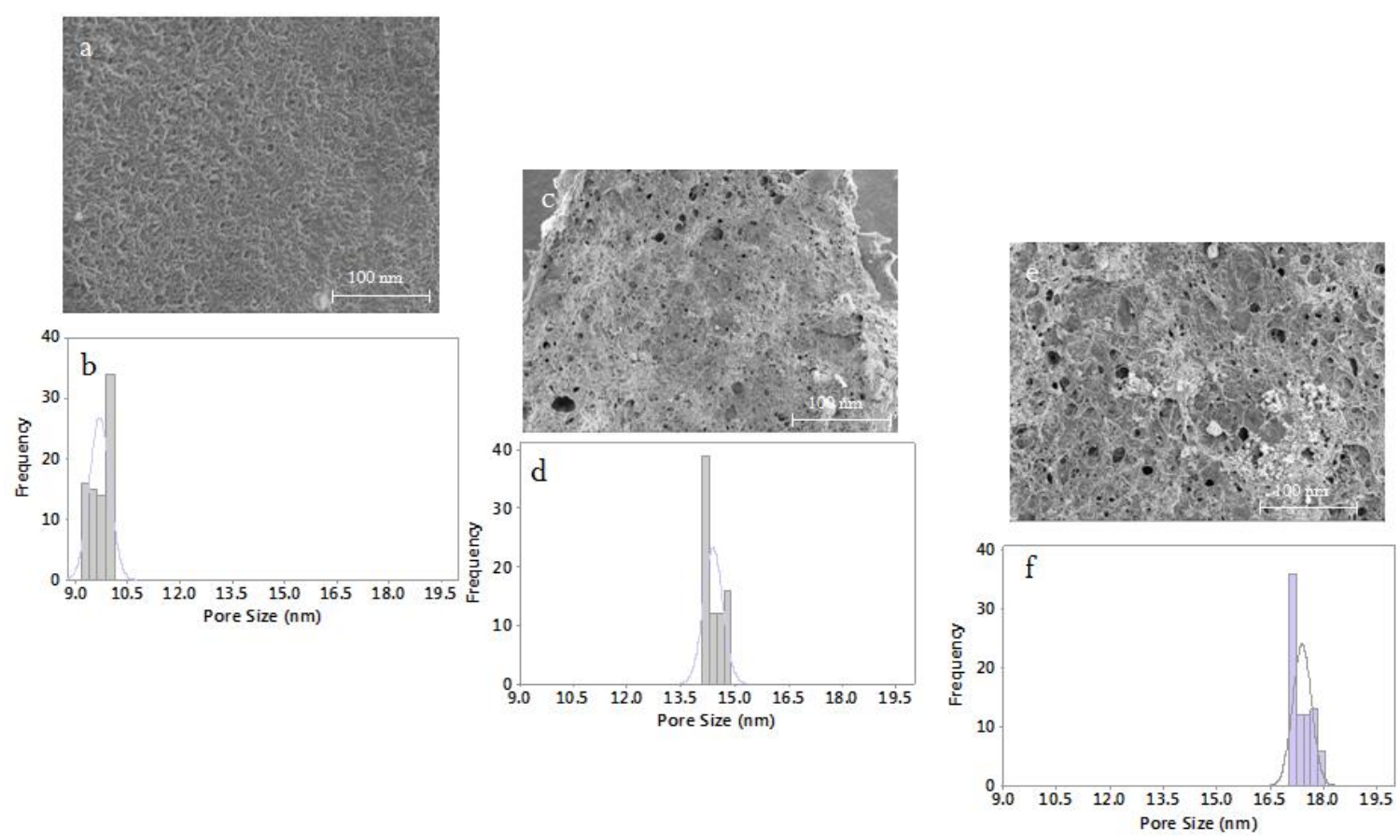

Figure 2. SEM images, pore size distribution of (a, b) NCLCS at $23^{\circ} \mathrm{C}(\mathrm{c}, \mathrm{d}) \mathrm{NCLCS}$ at $30^{\circ} \mathrm{C}(\mathrm{e}, \mathrm{f})$ NCLCS at $60^{\circ} \mathrm{C}$
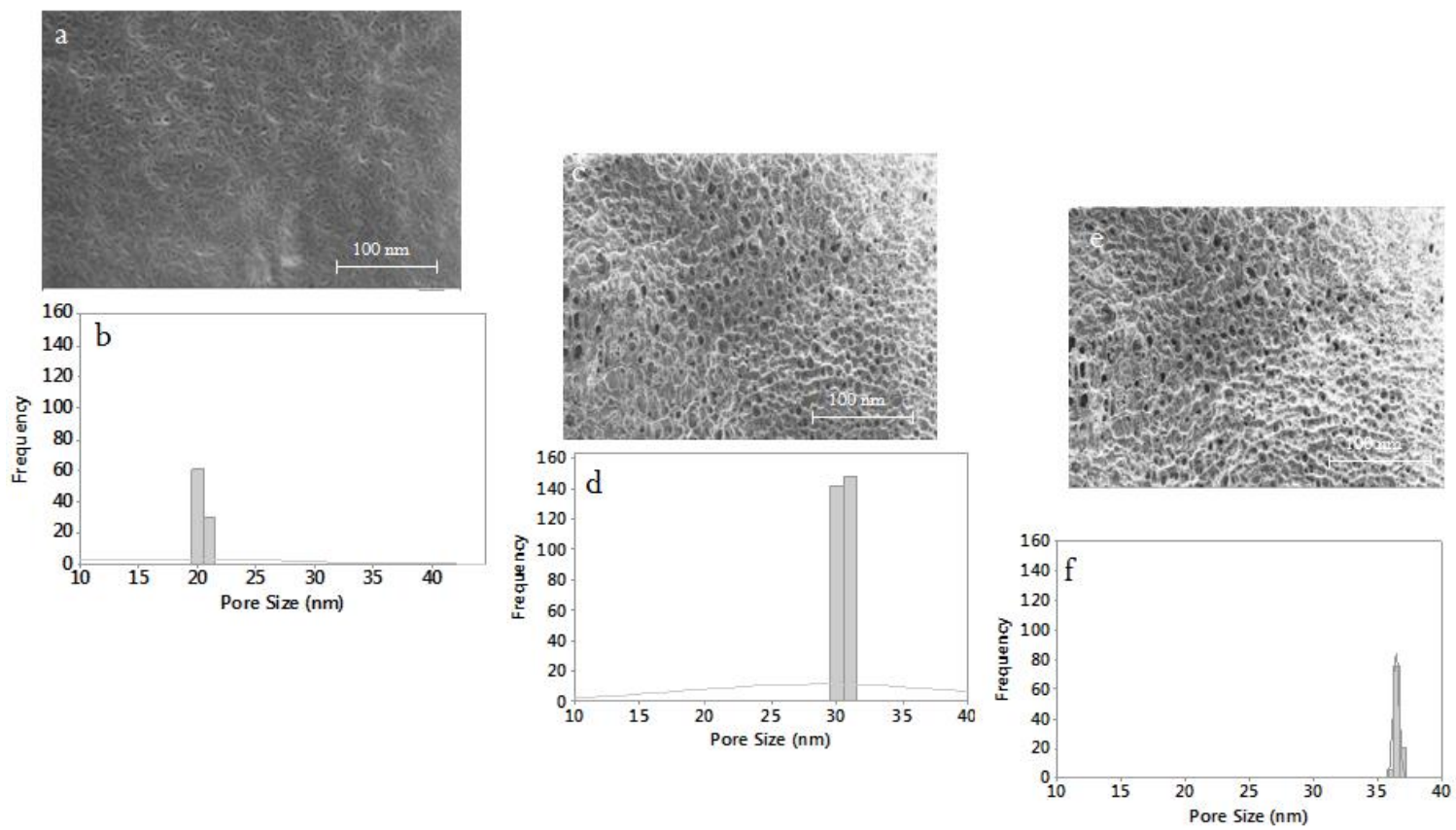

Figure 3. SEM images, pore size distribution of $(a, b) \mathrm{CLCS}$ at $23^{\circ} \mathrm{C}(\mathrm{c}, \mathrm{d}) \mathrm{CLCS}$ at $30^{\circ} \mathrm{F}(\mathrm{e}, \mathrm{f}) \mathrm{CLCS}$ at $60^{\circ} \mathrm{C}$

\section{Copyrights}

Copyright for this article is retained by the author(s), with first publication rights granted to the journal.

This is an open-access article distributed under the terms and conditions of the Creative Commons Attribution license (http://creativecommons.org/licenses/by/3.0/). 